Revista de la red interuniversitaria de estudios sobre las literaturas rioplatenses contemporáneas en Francia

23 | 2021

La vereda de enfrente. Cruces entre las literaturas argentina y chilena del siglo XX

\title{
La forma del secreto: Silvina Ocampo, María Luisa Bombal, Marta Brunet
}

La forme du secret: Silvina Ocampo, María Luisa Bombla, Marta Brunet

Tracing the forms of secret: Silvina Ocampo, María Luisa Bombal, Marta Brunet

\section{Ana Traverso}

\section{OpenEdition}

Journals

Edición electrónica

URL: https://journals.openedition.org/lirico/11302

DOI: $10.4000 /$ lirico. 11302

ISSN: 2262-8339

Editor

Réseau interuniversitaire d'étude des littératures contemporaines du Río de la Plata

Referencia electrónica

Ana Traverso, «La forma del secreto: Silvina Ocampo, María Luisa Bombal, Marta Brunet», Cuadernos LIRICO [En línea], 23 | 2021, Publicado el 09 diciembre 2021, consultado el 07 enero 2022. URL: http:// journals.openedition.org/lirico/11302 ; DOl: https://doi.org/10.4000/lirico.11302

Este documento fue generado automáticamente el 7 enero 2022.

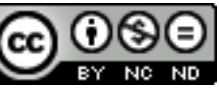

Cuadernos LIRICO está distribuido bajo una Licencia Creative Commons Atribución-NoComercialSinDerivar 4.0 Internacional. 


\title{
La forma del secreto: Silvina Ocampo, María Luisa Bombal, Marta Brunet
}

\author{
La forme du secret: Silvina Ocampo, María Luisa Bombla, Marta Brunet \\ Tracing the forms of secret: Silvina Ocampo, María Luisa Bombal, Marta Brunet
}

\section{Ana Traverso}

1 La literatura tiene siempre algo de secreto, en tanto su sentido es difícilmente traducible y reducible a un contenido explícito. Se traduce la literatura, dirá Jacques Derrida, pero algo también está destinado a resistirse a esa traducción: "cuanto queda intraducible sería más estrictamente literario" (2007: 24). Es propio de la existencia, del lenguaje y de las palabras, afirma José Luis Pardo, ser "incapaces por sí solas de atenerse a un significado único e invariable" (96), "porque ni los seres humanos tienen una identidad natural ni las palabras un significado explícito literal o recto" (96). Ese "secreto a voces" del que habla Pardo como constitutivo de la cara "íntima" del lenguaje, es lo que ha explorado la literatura en todas sus épocas ${ }^{1}$.

2 Según las corrientes y formas narrativas, el lugar del secreto ocupará en el relato distintos grados de importancia, y desarrollará variadas aristas según las aproximaciones estéticas epocales. Si en el siglo XIX el secreto podía llegar a tener un valor negociable y era capaz de reorientar la política de un país -al tratarse de información privada relevante que una vez conocida públicamente terminaba desencadenando grandes tragedias nacionales²-, los secretos del siglo XX, más íntimos, más silenciosos, menos bullados y comprensibles pero con consecuencias igualmente trágicas, ocuparán en muchos casos el centro del relato, girando alrededor del "vacío de eso que no está dicho" (Piglia: 250), sin llegar tampoco a revelarse. Los secretos del siglo XIX pertenecerían mayoritariamente al orden de lo que José Luis Pardo llama la privacidad: la cara opuesta de lo público; aquello que "pudiendo ser público permanecería en reserva y oculto por razones morales, estéticas, etc., variando su frontera según el pacto social que determine cada grupo humano" (97). Así, y tal como lo ha abordado Doris Sommer en Ficciones fundacionales, en este mundo de las elites 
políticas y económicas, las consecuencias del amor, el erotismo y los deseos, terminarán repercutiendo en los pactos sociales y las alianzas estratégicas de la comunidad. El secreto del siglo XX, en cambio, pareciera colindar con lo que Pardo define como intimidad: "la cara interna del doblez del lenguaje o del sujeto, en donde residen la distinción -la falta de identidad- personal de los hombres y el sentido implícito -la falta de significado- de las palabras, cosas ambas que son estrictamente íntimas" (97). Preocupaciones de la narrativa del XX: la pregunta por la mismidad del sujeto y la univocidad del lenguaje. No se trataría solo de un cuestionamiento del régimen de verdad de la ley y el pacto social, en el interés por abordar la incidencia que la ley pudiese tener en los espacios domésticos, familiares, privados; se buscaría más bien entrar en "el contenido no informativo del lenguaje" (97), en los silencios y en las alusiones implícitas, aquello "que no puede ser objeto de contrato ni de convención explícita, algo sobre lo que no cabe pacto alguno" (97). En el ámbito de lo íntimo, dice Pardo, cada "palabra dicha tiene siempre un plus de sentido o, en términos más rigurosos, una cantidad inagotable o una multiplicidad inexhausta de sentido, siempre quiere decir más de lo que dice y nunca puede decir todo lo que querría" (97).

En el ámbito de lo incomunicable del lenguaje humano, su intimidad y su misterio, Luisa Valenzuela, en su ensayo Escritura y secreto, explora lo que ella define como una de las preocupaciones centrales de la literatura. Para la escritora argentina, habría algo que le interesa particularmente a la literatura y tiene que ver con lo que está más allá de las palabras, "pero un pasito apenas" (202: 14). Sería aquello "[R]eservado, oculto incluso para nosotros mismos" (15), frente "al más desgarrador e intenso de los secretos, aquel que nos pondría en contacto con el meollo del conocimiento" (15). Quien escribe buscaría "aproximarse al corazón de lo inefable", es decir, a "aquello que no puede ser dicho con palabras, aquello para lo cual todo el vocabulario humano y su casi infinita combinatoria no alcanza" (15). Pero, al mismo tiempo, no se trataría de "develar el Secreto condenándolo a la muerte, más bien darle oxígeno, avivarle la llama intentando ir más allá, plus ultra, porque el Secreto es unívoco y múltiple, y cuando alcanzamos a sacar algún secreto a la luz, con suerte aparece otro y otro, en cadena, para preservar la esencia" (25). En este sentido, dice Valenzuela, al adentrarnos en la literatura se rodea el Secreto sin violentarlo, para no "desgarrar el velo, sino simplemente de apenas descorrerlo unos milímetros"; "el velo siempre caerá en otra parte haciéndonos notar -sin develarla- otra zona oscura del misterio" (29). En el umbral del Secreto "conviene detenerse allí y no cruzarlo, es decir, conviene no intentar explicar aquello que uno al escribir cree haber atisbado porque empalidecería la poca luz lograda" (29).

4 A partir de esta breve introducción me interesa enfatizar el vínculo entre literatura y secreto, y destacar no solo aquel elemento general e inherente del lenguaje, que lo vuelve intraducible, sino también la preocupación por tematizar el secreto: sea revelando lo oculto, o manteniéndolo en el centro del relato, como un elemento articulador de la trama, que se organiza a partir de aquello ausente. Ricardo Piglia, como aparece mencionado más arriba, ha estudiado la relación entre secreto y narración para el caso de la nouvelle. Acá me interesa abordar algunas narrativas -más allá de sus modalidades genéricas- de mediados del siglo $\mathrm{XX}^{3}$ que pondrían el secreto en el centro de su preocupación, merodeándolo y tratando de acercarse a aquello velado a través de la confidencia o el espionaje, desplazando el secreto, en ambos casos, unos pasos más allá sin lograr conocerlo. Confidentes o espías, dos caras de la misma moneda, tratan de averiguar aquello que se escurre y que pareciera quedar en nada; 
aunque en estos intentos por decir o conocer se va desplegando una apuesta metaliteraria que abraza íntimamente lo indecible en este juego de darle forma al secreto por medio de espejos, dobles, cajas, proyectadas al infinito.

Quisiera entonces establecer ciertas relaciones en el modo en que abordan el secreto tres autoras que, al menos, en algunas de sus obras hacen ocupar a lo indecible un lugar central. Las confesiones de los personajes de Silvina Ocampo en varios de sus cuentos de La Furia (1959) y Las invitadas (1961) -y ya antes en Viaje olvidado (1937)- postergan y desplazan la revelación, abriendo con ello la puerta a nuevos secretos; mientras que el secreto en su nouvelle "El impostor" (publicada en 1948 en Autobiografía de Irene), sin lograr desentrañarse, devuelve al sujeto que lo persigue el reflejo de su mirada de espía. La niebla y los sueños son el ambiente de opacidad en los que María Luisa Bombal, por su lado, bordea los secretos de las mujeres o de los hombres que las observan, también en este juego especular de las miradas, particularmente en su nouvelle "Las islas nuevas" (1939). Por último, quisiera detenerme en la novela Amasijo (1962) de Marta Brunet, donde la autora, junto con abordar la pregunta por la identidad sexual, asimilándola a la imagen de una masa informe, va tejiendo una trama que entrelaza distintos momentos temporales, varios planos narrativos, cruces de confesiones que mezclan la ficción, la autobiografía, el drama y el psicoanálisis, quedando así suspendida cualquier revelación sobre el misterio del deseo y la diferencia sexual.

6 Se trata de tres escritoras de la misma generación que orbitan en distintos momentos alrededor de la revista Sur, y que aunque no hayan estrechado vínculos entre ellas, este espacio será una importante vitrina para mostrar su trabajo y posicionarse en un campo cultural aún restrictivo para las mujeres. No quisiera sugerir con esto que la revista sirvió para unir sus preocupaciones; ni tampoco pretendo trazar una relación causal entre ellas a través de la revista, ni plantear semejanzas en ciertos momentos de sus trayectorias. Más bien busco detenerme a analizar cómo se aproximan estas autoras al secreto, y desde ahí pensar una posible reflexión metaliteraria que podría dar luces sobre sus opciones estéticas y posicionamientos literarios.

7 Pero antes quisiera hacer una sucinta presentación de las autoras y de los textos que analizaremos. Silvina Ocampo se sitúa desde su primera publicación, Viaje olvidado (1937), como la gran maestra del arte de insinuar secretos. Vinculada a lo ominoso freudiano por su cercanía con el horror dentro del espacio familiar, irá -en los libros posteriores- perfeccionando una técnica del secreto; una especie de retórica de la paradoja, cuyo sentido se vuelve secreto por su imposibilidad de resolverse. Artificio por lo demás muy acorde con la irresolución de lo fantástico, y que Podlubne ha explicado como el acato de Ocampo a los principios estéticos de la revista Sur, a partir de su segunda publicación Autobiografía de Irene (1948). Tal como ha enfatizado la especialista, con los libros que le siguen, La Furia (1959) y Las invitadas (1961), Ocampo recuperaría esa voz original de la primera obra -en el tono coloquial, irónico y en el mundo tan personal de sus personajes-, sumando además, en algunos de sus cuentos, ese "secreto paradojal" más del orden de una retórica de lo fantástico.

María Luisa Bombal, en tanto, desarrolló una parte importante de su obra en Buenos Aires, muy cercana a Sur y al ambiente intelectual que circulaba en torno a la revista. Su primera novela, La última niebla (1935), la escribe y publica en Argentina; La amortajada (1938) ya aparece bajo el sello de la editorial Sur, lo mismo que sus cuentos "El árbol" (1939) y "Las islas nuevas" (1939). Colabora asiduamente en la revista y a propósito de una crítica de cine se introduce en la escritura del guion cinematográfico. 
Desde sus inicios su prosa exuda esa nebulosa ambigüedad que lleva a confundir los sueños con la realidad, la vida con la muerte, el pasado con el presente. La separación del mundo de los hombres y las mujeres -preocupación central de su narrativa- aunque quisiera delimitarse con mayor precisión, pronto se insinúa que ese terreno -el de la diferencia sexual- es un misterio que parece no poder resolverse. Tal como las islas que Bombal vio en la pampa argentina emerger y desaparecer enigmáticamente, imaginó una mujer ' $\tan$ misteriosa como la naturaleza que los hombres 'no' comprenden ni quieren comprender. Yolanda, jpobrecita!...” (2018: 289).

La narrativa de Marta Brunet, que había comenzado con una poética de crítica social en la década del '20, se vuelve una evidente apuesta intimista con la publicación de Amasijo el año 1962, una de sus últimas obras. Es el tono de los sesenta. Y con esta novela, de claro tinte existencial, Brunet se suma a la pregunta por la construcción de la subjetividad, por la diferencia sexual y por la orientación del deseo que concentró a toda la generación. A través de la imagen del "amasijo", esa mezcla informe hecha de harina y agua, elementos comunes y familiares, se representa la identidad del sujeto cuyo sentido se vuelve imposible y misterioso para él mismo. Lo familiar que constituye al sujeto deviene extraño y amenazante en los vínculos que establece con el pasado, a través de escenas reprimidas que reaparecen en la vida presente, en los continuos desdoblamientos y despersonalizaciones, en el modo de relacionarse con la realidad que lo circunda, volviendo confuso y extraño lo que percibe y lo que escribe.

Queremos pensar que los textos de estas tres autoras -probablemente, las más importantes narradoras del momento en sus respectivos países, aunque no necesariamente las más reconocidas- sugieren ciertas decisiones estéticas en su acercamiento al secreto. ¿En qué cambia la entrada al secreto desde la opción más formalista de "El impostor" (1949) a la que ha sido reconocida como su más genuina y personal apuesta en textos como Viaje olvidado (1937), La Furia (1959) y Las invitadas (1961), para el caso de Silvina Ocampo? ¿Si no fue su voz la que habló en "El impostor", sino aquella "impostura" literaria para ser aceptada por el círculo borgeano, los secretos también tendrían que ver con aquel desdoblamiento? ¿Qué secretos, en cambio, se revelan cuando privilegia su mirada más personal? ¿Si la intensa pero exigua obra de Bombal mantiene ese enfoque nebuloso y onírico (que decae tal vez en las últimas narraciones), habría un mismo modo de abordar lo secreto entre sus creaciones? Y para el caso de Brunet, ¿los posibles secretos del criollismo, si los hubiera, trascienden el criollismo o son los propios límites en que se detiene el criollismo? ¿Los secretos de Amasijo (1962), en esa misma línea, tienen relación con la experimentación existencial?

11 En síntesis, ¿a qué secretos nos acercamos desde los umbrales de la retórica literaria, desde las modas o corsé estéticos, desde unas determinadas formas narrativas? ¿Qué hay más allá de las formas narrativas, qué no se puede decir, cuáles son sus silencios? Anticipando una posible respuesta a la pregunta por el vínculo entre el secreto y el modo narrativo (y su tendencia estética), me parece que algo en estos textos se juega en el borde de las formas narrativas, que las pone en tensión, en el abismo, en los límites de la posibilidad de decir, cuestionando precisamente esas seguridades formales $\mathrm{y}$, a su vez, disponiendo una mirada tentativa a la pregunta por el sujeto.

12 Comenzaré con la lectura de "El impostor" (1948) de Silvina Ocampo y "Las islas nuevas" (1939) de María Luisa Bombal, al compartir ambos textos la difusa relación entre sueño y realidad, y la preocupación por reflejar la mirada en una suerte de juego 
de espejos. En la segunda parte, volveré a Silvina Ocampo para esta vez revisar algunos de sus cuentos de La Furia (1959) y Las invitadas (1961) bajo el prisma de la confesión. Los narradores de estos relatos son personajes que persiguen desesperadamente la confidencia para entender y conocerse, como también lo es el protagonista de Amasijo (1962) de Marta Brunet. Entre espías y confidentes se mueven los personajes de estos relatos en el intento por develar el secreto.

\section{Los dobleces del secreto}

El tan visitado tema del doble en la literatura, sobre todo en la tradición fantástica, es comprendido por Luisa Valenzuela como uno de los modos más recurrentes de acercarse al secreto de aquella "imposibilidad humana: la mismidad. Somos nosotros y el otro, aquel que dormita en la penumbra inconsciente y en cualquier momento despierta de un salto y se convierte en amenaza" (2002: 40). Llevando al extremo este recurso literario, Silvina Ocampo, en "El impostor" (1949), ensaya con reduplicar toda voz narrativa en un doble invertido, en un doble amenazante que traiciona al yo al espiarlo para, en algún momento, acusarlo al padre. Si hay un "impostor" habría uno "legítimo"; pero esa distinción parece difuminarse y vuelve la pregunta por la autoría literaria a la ausencia de origen y, con la amenaza vigilante del padre, a una especie de "angustia por la influencia" (Bloom). No es gratuito entonces que "El impostor" haya sido considerado por la crítica el texto menos "auténtico" y "original”; el más seguidor de las prescripciones de Sur, si la propia autora -además de adherir a la figura ya instalada del doble- explicitaba abiertamente sus dudas respecto a la originalidad en la literatura. No había ningún secreto en ello: la autora, con esta apuesta por la negación de todo origen, asumía así su propia escritura de "impostora".

El texto, en gran parte, es la narración de José Maidana, un joven estudiante que es enviado a una finca para espiar a otro joven, Armando Heredia. La misión la solicita el padre de Armando, quien sospecha del encierro de su hijo en esa casa vieja y abandonada, elucubrando el ocultamiento de un secreto vinculado a vicios, como una mujer o excesos de alcohol. El padre le encomienda al narrador que observe y le reporte información, volviendo la narración una especie de informe detectivesco, por una parte, y la historia de la progresiva amistad que va surgiendo entre los dos jóvenes, por otra, no sin continuas tensiones y suspicacias. La propia situación de espionaje supone un caso y un secreto que debe detectarse, instalando la desconfianza entre ambos. Así es como Maidana descarta prontamente el móvil de la mujer y el alcohol como explicación del aislamiento del joven Heredia, y, más bien, va descubriendo una tendencia a la soledad y a la austeridad, muy opuesta a la hipótesis del padre. Pero otros son los misterios que esconde el personaje. Niega conocer e interesarse por una mujer que luego resulta ser la persona que lo/él invita a encuentros, al parecer, amorosos. Maidana descubrirá que la mujer no acude a las citas, aunque su amigo insistirá en haberla visto. Averigua, además, por conversaciones con la gente del pueblo que ella habría muerto cuatro años atrás, y al enfrentar a Heredia con esta noticia, este se defenderá argumentando que para él, ella nunca habría fallecido. Maidana entonces comienza a alimentar la tesis de la locura de Heredia y se resuelve a escribirle al padre con las novedades, cuidándose de que su amigo no descubra la traición. Pero Maidana no tiene completa seguridad de lo que percibe. A él mismo le ocurren situaciones curiosas que no sabe muy bien cómo explicar. Descubre objetos, personas, escenas que 
ya ha soñado o que anticipa en sueños, las que luego se reproducen con mínimas variantes en la realidad. Lo fantástico del relato se tiñe entonces con el tinte policial cuando el enfrentamiento de los jóvenes -a propósito de la carta que Maidena pretende enviarle al padre de Heredia- desata una discusión con amenazas de disparos y huidas por el predio.

Gracias a un segundo narrador, Rómulo Sagasta -otro amigo enviado por el padre para espiar al hijo-, nos enteramos que Heredia habría muerto un día antes de su llegada y que Maidana nunca habría existido. La tesis que se propone demostrar este nuevo narrador -y que requiere de su final explicativo- es que el primer relato correspondería al diario íntimo de Armando Heredia, titulado "Mis sueños", en el cual daría cuenta de sus alucinaciones y desdoblamientos. Maidana, entonces, sería un personaje imaginario: el doble de Heredia.

La crítica ha enfatizado suficientemente la relación de este cuento con los preceptos de Borges, Sur y lo fantástico. El cazador que termina cazado; el soñador que es soñado por otro; el salvador que termina siendo destruido por quien quiere salvar; son polos de un mismo sujeto que no logra unificarse, que escribe para (des)conocerse. Al tratamiento del doble en este enfrentamiento de las dos caras de un sujeto en el espejo, a partir de la personificación de estos amigos-enemigos que se terminan (auto)destruyendo, se suma la figura del espejo sin fin o infinito con la aparición del segundo narrador. Este es igualmente enviado por el padre y tampoco logra rescatar al hijo de la autodestrucción, interviniendo la escritura del diario para darle un final. Pero no solo buscaría cerrar esta narración inconclusa -con la información de la muerte de Heredia/Maidana-, sino que en estas indefiniciones de lo real y lo soñado termina por creer que la narración es obra suya: "A veces pienso que en un sueño he leído y he meditado este cuaderno, y que la locura no me es ajena" (2017: 153). Rómulo Sagasta podría pensarse como el doble de estos dobles en un juego de espejo infinito. Es más, si tomamos en serio esta reflexión habría que extrapolarla a nuestra propia experiencia de lectura y pensar incluso que pudimos haber soñado el relato: "No hay distinción en la faz de nuestras experiencias; algunas son vívidas, otras opacas; algunas agradables, otras son una agonía para el recuerdo; pero no hay cómo saber cuáles fueron sueños y cuáles realidad" (153). Si esto fuese así, tal como dice el segundo narrador, "[L]as consecuencias de cualquier hecho son, en cierto modo, infinitas" y este relato se proyectaría indefinidamente en el juego de espejos sin fin que se sugiere.

Luisa Valenzuela distingue los secretos con minúsculas -aquello que la gente guarda y que son asuntos comunes y vulgares, los que llama, "secretos fisiológicos", "esas vergüenzas que pertenecen al orden de lo privado (...) minúsculos algunos, verdaderos antisecretos que carecen de interés" (Valenzuela 2002: 17)- y el Secreto con mayúscula. El padre de Armando, en este sentido, andaría detrás del secreto con minúscula -la mujer o el vicio-, y utilizaría a Maidana, primero, y a Sagasta, después, para descubrirlo. "No puede tolerar que yo esté aquí", dice Armando. "Sospecha que le oculto un secreto. ¿Acaso puede uno vivir sin ocultar un secreto a su padre?" (Ocampo 2017: 112). El padre sabe que no obtendrá una confesión de su hijo, y tampoco podría pedirle a Maidana que "aprovechando las ventajas de una posible amistad", "arranques de su corazón un secreto para entregármelo a mí" (107). Pero confía en cambio que hay algo que puede llegar a saber, vía Maidana o Sagasta. Ambos, en efecto, intentan descubrirlo, aunque solo parecen acercarse a un secreto mayor, imposible de conocer. Tal como lo propone Luisa Valenzuela, muchos “de estos secretos (mínimos) configuran 
a veces una huella oculta, pero huella al fin y, como tal, transitable, que por momentos puede acercarnos al Otro, el inasible, inefable Secreto de la vida y la muerte" (Valenzuela 2002: 17). Es lo que parece sugerir Armando cuando, a propósito de la curiosidad de su padre, dice: "Suponiendo que lo averiguara (el secreto) y lo descubriera, siempre existiría un secreto. Nunca podría conocerme" (Ocampo 2017: 112). La búsqueda del secreto del Otro parece tantear los misterios y oscuridades que esconden quienes buscan; lo que todos esconderíamos sin saberlo. Y la figura del doble, en este sentido, podría ser pensada como el acercamiento al Otro que revela y devuelve la imagen de la imposibilidad del autoconocimiento. Maidana, en su intento por acceder a Armando, se va sorprendiendo con los misterios de sus propios sueños y deseos. Mientras Sagasta, al abrir el diario de Heredia-Maidana, se aproxima al problema de la autoría en la relación escritor-lector.

Ni Maidana ni Sagasta satisfacen al padre con sus investigaciones y sus reportes, si bien ambos le rinden cuentas detalladas. A través de una carta, el primero, donde, aunque no está seguro, cree encontrar una explicación en la locura; mientras el segundo, además de revisar el diario de Heredia-Maidana y contrastar esa versión con evidencias y entrevistas, elabora un informe y se reúne con el padre para explicarle el misterio del desdoblamiento y el posterior suicidio de su hijo. Pero ni la locura, ni el desdoblamiento, ni el suicidio parecen interesarle al padre, ni menos lo que hay detrás de ello. De este modo, lo que abre el Secreto con mayúscula, el padre se apura en clausurarlo, dando vuelta la página con un definitorio: "Fue mejor que Dios se lo llevara; muchachos de esa clase no hacen nada bueno. Ya costó bastantes llantos a su madre" (152). El padre se ha proyectado (desdoblado) en Maidana y Sagasta, porque sabe que no puede arrancarle el secreto a su hijo. Pero una vez delante de los espejos que sus espías le presentan, el padre prefiere apartarse, rechazando el reflejo que estos le ofrecen, desviando la mirada de la posible figura suya que pudiese encontrar allí, negando así cualquier responsabilidad. El espejo invertido que se despliega en la relación Heredia-Maidana, o el espejo infinito que se proyecta desde Sagasta a los lectores en esta apropiación del texto Heredia-Maidana, son las dimensiones del Secreto que abre, sin embargo, la curiosidad del padre. ¿Qué es Maidana para Heredia si no la mirada del padre que lo persigue? ¿No es su muerte o suicidio la imposibilidad de escapar del ojo del padre? Cuando afirma "mataría de un balazo a cualquier persona que pretenda meterse en mi vida privada" (115), el asesinato se vuelve necesariamente contra sí mismo, contra esa mirada espía del padre (la ley paterna). Desde la lectura que presenta Sagasta, ¿Heredia asesina al fantasma de su padre vestido de Maidana, al espía de sí mismo que lo persigue traspasando cualquier encierro? ¿Por qué Sagasta, entonces, incorpora una versión en donde él (Sagasta) sería el asesino? Así lo plantea:

Si yo hubiera llegado a Los Cisnes el 26 o 27 de enero en lugar del 28, como quería hacerlo, hubiera salvado con el fantasma de Maidana a Armando Heredia, pero tal vez hubiera perdido mi propia voz. Y si esto fuera una historia policial, yo habría sostenido, tal vez, una disputa con Armando; éste (como en la realidad) se habría suicidado y me acusaría criminalmente de su muerte (153).

Con esto, Sagasta se apropia del texto de Maidana ("mi propia voz") y de la muerte de Armando, siendo ahora él el autor del crimen y del texto. En este juego de espejos, el asesinato de Armando a Maidana se vuelve sobre sí mismo (suicidio), y al asumir Sagasta la autoría del texto, se transforma en el crimen del autor contra su personaje. Maidana, en tanto espía del padre o el doble de Heredia, apunta a la idea de buscar con los ojos del padre aquel secreto, aquella culpa que instala la ley del padre. El sujeto, se 
entiende acá, en su dimensión relacional padre-hijo; autor-personaje. Pero así como el personaje de Sagasta podría acusar a su autor de asesinato aunque fuese suicidio, podría decirse también que en el suicidio de Heredia está el claro deseo de matar al fantasma del padre (en la figura de Maidana). Una narración reversible, donde todo lo que se afirme puede invertirse al infinito, en la línea de los textos que estudia Lucien Dällenbach en El relato especular (1977).

\section{El secreto de la diferencia sexual}

"Las islas nuevas" (1939) de María Luisa Bombal comparte con el relato de Ocampo el ambiente gótico de la casa y las escenas de las que no se sabe con exactitud si son reales o soñadas. Islas que aparecen y desaparecen son el marco en que se mueven los personajes, reunidos en esta finca precisamente para ver cómo emergen estas misteriosas islas. Yolanda, única mujer del relato, se recuesta sobre su brazo izquierdo y tiene extrañas pesadillas que la remontan a tiempos originarios, prehistóricos. El resto de los personajes -el hermano de Yolanda, un antiguo pretendiente y un nuevo enamorado- gira alrededor de Yolanda y sus pesadillas, tratando de descifrarlas y descifrarla a ella, como si fueran la misma cosa. Intrigado Juan Manuel -uno de los invitados y progresivo enamorado de Yolanda-, la observa detenidamente, sin lograr precisar a qué se parece. Entretanto, sopesa alternativas: una culebra, una serpiente, una gaviota, un ala, sin dar con el parecido.

21 El texto ha sido leído bajo el prisma de la diferencia sexual, y las distintas lecturas coinciden, en general, a la hora de identificar cierta "mitificación" de la esencia femenina en el vínculo de Yolanda con las islas, la naturaleza, los mitos originarios y los sueños. Por su parte, los varones parecen inclinarse por las actividades tradicionales, la caza, la conquista y el conocimiento, en este intento por desentrañar a la mujer, aunque sea frustradamente. Un mundo donde las mujeres son un misterio para los hombres y donde ellos son "absurdos", "siempre dispuestos a interesarse por todo", "listos para huir siempre hacia cosas fútiles" y "temerosos del silencio como de un enemigo" (2018: 148). Yolanda además los piensa con desdén, cuando "entre diez cazadores no han podido cazar" y en la cena "devoran precipitadamente" (149).

Pero a la luz del "El impostor" de Ocampo, las diferencias de género que aborda el texto de Bombal podrían plantearse también a modo de dobles invertidos o espejos, que orbitan en torno a un secreto. A primera vista, el secreto tiene que ver con la mujer que duerme sobre el lado izquierdo y sufre de recurrentes pesadillas. Para los hombres que la observan, el misterio de los sueños se asocia a su peculiar físico y una edad indefinible. Tal como Maidana cree reconocer en Heredia a alguien que no recuerda: "no era como yo lo había imaginado, pero en cambio se parecía a alguien" y "no podía descubrir a quién" (108); y una y otra vez vuelve "a asociar su cara a otras caras, en vano" (110); asimismo Juan Manuel insiste en buscarle un parecido a esta mujer con distintos elementos, hasta creer dar con la pista: una gaviota. Al mismo tiempo que lo piensa, se lo dice a ella, quien, tras un "gritito ronco, extraño" (156), se desmaya. Intenta explicarles a los demás lo sucedido, sintiéndose "culpable de algo que ignora, temiendo sin saber por qué, revelar un secreto que no le pertenece" (156). La carta de la mujer, los sueños, su parecido con algo indefinible, todo le parece raro; mucho más que las islas que aparecen y desaparecen. Pero será el descubrimiento del muñón de ala en el hombro derecho de la mujer lo que terminará por horrorizar a Juan Manuel y hacerlo 
huir despavorido a Buenos Aires. Un muñón, un miembro atrofiado, que más dice del miedo de Juan Manuel al sexo femenino y su castración, que del cuerpo de la mujer:

Yolanda está desnuda y de pie en el baño, absorta en la contemplación de su hombro derecho.

En su hombro derecho crece y se descuelga un poco hacia la espalda algo liviano y blando. Un ala. $O$ más bien un comienzo de ala. 0 mejor dicho un muñón de ala. Un pequeño miembro atrofiado que ahora ella palpa cuidadosamente, como con recelo.

El resto del cuerpo es tal cual él se lo había imaginado. Orgulloso, estrecho y blanco.

Frente al espejo, Yolanda mira su hombro derecho, y en él parecen reflejarse los temores masculinos sobre su sexualidad y potencia. El pequeño miembro atrofiado en el hombro de la mujer será, para Juan Manuel, "el dulce y horroroso secreto" de Yolanda. Lo que intentaban adivinar con cartas, parecidos y sueños está ahí, descubierto, igualmente misterioso y enigmático. Igualmente indescifrable.

Si Juan Manuel se siente progresivamente obsesionado con la mujer, en esta constante observación, ella parece estar entregada a su deseo por Juan Manuel. Sueña que él le habla al oído y la toma en sus brazos: "Y ahora los brazos que la estrechan por la cintura tiemblan y esbozan una caricia nueva. ¡Va a tocarle el hombro derecho! ¡Se lo va a tocar! Y ella se debate, lucha, se agarra al alambrado para resistir mejor. Y se despierta aferrada a las sábanas, ahogada en sollozos y suspiros" (153). Un sueño que parece implicar, coincidentemente con la visión que tendrá Juan Manuel, a ese muñón en el hombro, asociado al deseo.

Nuevamente la misma escenografía, la tranquera, es ahora el espacio de encuentro, pero esta vez "en carne y hueso" (154). Desde los dientes, su aroma y la contextura, todo le parece hermoso y fuerte en este hombre. Al ser llamada por su nombre, fantasea con la idea de compartir "un largo pasado de deseo" (155), y se anima a confesarle que "he soñado con usted, Juan Manuel, toda la noche..." (155), permitiéndole "enlazarla castamente por la cintura" (155). Esa noche, él se atreve a entrar al cuarto de Yolanda mientras ella duerme y la ayuda a desprenderse de una de las pesadillas. Comienza a relatarle su sueño ambientado en paisajes prehistóricos, dominados por el silencio, hasta que recae en que el hombre ha invadido la privacidad de su cuarto. Preparado para ser expulsado del lugar, se sorprende cuando ella se recuesta sobre su pecho, y entonces él la toma y la desnuda por la fuerza.

Con esta descripción de los acercamientos amorosos de la pareja, he querido dar cuenta de los sueños y el deseo de Yolanda, que Juan Manuel no parece comprender. Más bien, huye a su casa en Buenos Aires, duda si lo que vio en el hombro de Yolanda fue producto de una alucinación o no, y ya a salvo en casa de su madre, con la protección del recuerdo de su esposa muerta y la placidez de su hijo, se detiene sobre la página abierta de una enciclopedia donde la descripción de la fase estelar de la tierra le recuerda a los sueños de Yolanda: "Yolanda, los sueños de Yolanda... el horroroso y dulce secreto de su hombro. ¡Tal vez ahí estaba la explicación del misterio!” (167). Pero contrario al interés u obsesión que ha manifestado por la mujer, temiendo "confundir las pistas, perder las huellas, caer en el pozo oscuro y sin salida para su entendimiento", "cierra el libro, apaga la luz, y se va" (167), "abandonando una vez más a Yolanda" (167).

27 Las posibilidades que abre el secreto, en los extraños sueños de Yolanda, en el muñón de su hombro, en el silencio al que ella parece invitarlo, Juan Manuel las clausura, primero, arrojándose sobre ella, luego huyendo de la estancia y, por último, cerrando el 
libro. Entre la mujer de la espesa cabellera negra con este misterioso muñón en el hombro, y el recuerdo de Elsa, la dulce, frágil y rubia mujer ya muerta, Juan Manuel opta por lo segundo, evitando así no caer a un pozo oscuro y sin salida para su entendimiento. Lo que resulta inaccesible para Juan Manuel parece estrellarse sobre un espejo que no hace sino reflejar la propia imagen de la cual se quiere escapar. Ante el miedo de los hombres - parece decirnos este texto que ilustra críticamente la mirada masculina- al secreto y lo desconocido -en esta pulsión por explicarlo todo-, la mujer queda deformada y resulta incluso una figura incomprensible.

\section{El secreto inconfesable}

La chilena María Luisa Portuondo descubrió en las cartas de su padre muerto un secreto familiar que hasta ese entonces nadie conocía. Guardó el secreto durante un buen tiempo, hasta que abrumada por su peso, se propuso no solo revelarlo al resto de la familia, sino hacer algo (humanitario, en cierto sentido) para liberar a otros de sus secretos. Como artista visual decidió hacer una instalación, que llamó "Secretos", en que todos aquellos que quisiesen desahogarse de sus secretos podrían escribirlos y guardarlos en un sobre para, posteriormente, en un acto de liberación colectiva, leerlos pública y anónimamente. Una especie de acción a lo Spencer Tunick, de poner en lo público la intimidad para superar el pudor, la vergüenza, y a partir de ahí crear una especie de comunidad efímera de nudistas sin secretos. Al escribirlos y leerlos dejarían de ser secretos, despojándose, los participantes, de su carga y culpa. A pesar de que la revelación del secreto supone habitualmente una escena de intimidad, la lectura pública del secreto aspiraría utópicamente a crear una comunidad de sujetos sin ocultamientos, sin pudores, sin dobleces, sin misterios, aceptados por el solo hecho de la desnudez como un atributo de la transparencia.

La performance de Portuondo buscaría contravenir la naturaleza misma de la palabra "secreto", que etimológicamente contiene los verbos se-parar (seleccionar, segregar) y analizar y distinguir. El "secreto" implica una acción de apartar para que no llame la atención, o donde no se pueda distinguir ni analizar. Así, contrariamente a la dirección que imponen los secretos, Portuondo buscaría ponerlos a la vista para ser leídos y compartidos a la comunidad. Pero, ¿pueden asimilarse los secretos desprendidos de su propia escena de confesión?, ¿pueden sacarse a la luz (pública) como si se tratase de una verdad esencial que constituye al sujeto y que posee una realidad anterior al discurso de confesión? En parte, lo que propone la artista es la negación misma del secreto, es el rechazo sin más del secreto, de todo secreto.

En una orientación opuesta, Derrida, en su conversación con Maurizio Ferrari, expone su gusto

del secreto, y eso indudablemente -afirma- tiene que ver con la no pertenencia; tengo un impulso de temor o terror ante un espacio político, por ejemplo, ante un espacio público que no dé espacio al secreto. Para mí, exigir que se dé a conocer todo y no haya un fuero interno significa volverse totalitaria la democracia. Puedo transformar en ética política lo que dije: si no se mantiene el derecho al secreto, se entra en un espacio totalitario. La pertenencia, el hecho de confesarla y de poner en común -trátese de familia, nación o lengua-, significa la pérdida del secreto. (1997: 81)

31 Pensar la confesión de un secreto como el intento de crear una comunidad aspira a que la revelación del secreto provoque una liberación, la desposesión de una carga de lo 
íntimo para depositarla en otro o en la comunidad y que ésta, de alguna manera, se haga cargo de esa confidencia, creando así una complicidad, una pequeña comunión, una cierta hermandad. Al mismo tiempo, esto supone que el secreto podría ser decible, compartible y comprensible. Pero además supone la existencia de un secreto guardado y en reserva, para ser dicho a alguien que "pone su oreja" y comprende lo dicho; un oyente que lo guarda y lo cree verdadero. Existiría, por tanto, una verdad previa a ser dicha, un hecho ocurrido pero que todavía no ha sido transformado en discurso. ¿Hay secreto antes de ser dicho?

Eloy Fernández Porta, en su libro La confidencia, relativiza esta idea, planteando que el "secreto solo existe en el instante de su confesión. Sucede en el lenguaje, y no antes, porque no hay ninguna realidad prelingüística. Ese instante, con su aura legendaria, tiene su contexto y su protocolo, articulado en torno a un vínculo entre el emisor y un receptor, que, al compartir el secreto, lo ponen a circular. Antes de ser expresado, no había secreto; en el momento en el que cobra forma se convierte en confidencia" (2018: 12).

Lejos de aquella utopía comunitaria de sujetos sin secretos, los cuentos de Silvina Ocampo escenifican mundos íntimos donde los secretos son constitutivos de la propia naturaleza del sujeto. Los personajes se construyen a partir de sus secretos, y conocerse, adentrarse en la intimidad, supone el esfuerzo paradójico de decir lo indecible, mostrar lo oculto, confesar lo que no se puede confesar. Como afirma Piglia, el secreto "es algo que se quiere saber y no se sabe", "es algo que alguien sabe y no dice", "el secreto es en verdad un sentido sustraído por alguien" (2014: 249). Pero si el secreto comienza a existir en el instante de su confesión (a otro), el propio sujeto se comprendería en su acto de habla, a partir de su discurso. Así, los sujetos hablan (o se hablan) para conocer ese "sentido sustraído", para escuchar/se, muchas veces en un desdoblamiento entre el adulto del presente y el niño del pasado. Es un secreto para el propio sujeto, quien no sabe todo de sí mismo y lo busca en la conversación con otro, o el otro que es él mismo, o que fue en el pasado. El secreto que comienza a circular en el acto de enunciación no tiene fin ni solución, en tanto se descubre en cada escena particular, en el habla-escucha con otro. Como una cadena interminable no habría solución para el secreto, ni liberación definitiva, ni menos la posibilidad de encontrar una verdad o un sentido final. Tal como afirma Fernández Porta: "No existe un modo correcto de examinar el propio secreto. Mírate: desconócete a ti mismo" (2018: 71).

Cada nuevo acto de enunciación del secreto revela nuevos secretos a la luz de la interpretación presente. El sujeto que confiesa se observa nuevamente -en presencia de un auditor- descubriéndose, desconociéndose a sí mismo a través de su secreto. El cuento "El pecado mortal" de Silvina Ocampo escenifica el desdoblamiento que acontece en la situación de confesión, literal y físicamente, al entablarse un diálogo -o más bien un monólogo recriminatorio- entre una voz adulta que se dirige a la niña que fue. La adulta enfrenta a la niña, en un claro desdoblamiento, desde el lugar de la autoridad y la "superioridad moral", enrostrándole sus faltas: "nadie sospechaba que la perversidad o más bien el vicio te apresaba ya en su tela pegajosa y compleja" (1961: 463). La autoridad que le confieren los años y la experiencia, le permiten (en teoría) nombrar y decir los tabúes y lo prohibido, que la niña aún no sabía cómo significar: "conociste en aquel tiempo el placer -diré- del amor, por no mencionarlo con su nombre técnico; tampoco tú podrías darle un nombre técnico, pues ni siquiera sabías 
dónde colocarlo en la lista de pecados que tan aplicadamente estudiabas" (1961: 463). La adulta le cuenta y explica a la niña lo que en su inocencia no pudo saber con exactitud.

Mientras la niña juega en el desván al cuidado de un sirviente -descrito por la adulta como "ladino" y "de mirada turbia"-, el hombre, ese día "más borroso que de costumbre", la invita a mirarlo a través del ojo de la cerradura. La clásica escena del voyerismo, con los tintes de la curiosidad femenina, se cifra en el "agujero de la cerradura" que -en palabras de la adulta- obraba "como un lente sobre la imagen vista”, y se tipifica aún más al compararla con el cuento "Barba Azul”: “¿Qué mujeres degolladas descubrirías?" (466). Ahí, tras la puerta y por medio de ese agujero estaba el "secreto" que no menciona la adulta porque la niña lo conoce y que lo compara ahora, en un impulso por referir a los clásicos, al amor prohibido entre Píramo y Tisbe. A pesar del detalle con que relata la posición de la niña en el acto voyerista, se ahorra decir qué vio; y así como describe el color de los dedos del hombre y su chaqueta lustrosa, solo sabemos que la niña "no se defendió" de lo que suponemos una violación. La niña guardó culposamente el secreto, elaborando informes mentirosos para su primera comunión, y la adulta no lo revela del todo en tanto supone que ella lo sabe. ¿Qué es lo que necesita decirle ahora de adulta? La tarea imposible de decir lo indecible, de confesar lo inconfesable se pospone nuevamente, revelando en esto lo que ha sido el secreto de la niña y de la adulta hasta ahora: su imposibilidad de perdonarse. Sin embargo, y en un acto extraordinario de desdoblamiento, le transmite su martirizada compasión, dando un giro radical a lo que ha sido su discurso de reproches y culpas: "Te buscaría por el mundo entero a pie como los misioneros para salvarte si tuvieras la suerte, que no tienes, de ser mi contemporánea" (467). La adulta, en el ejercicio de mirar y entender a esa niña inocente, descubre el deseo de salir de sí y perdonar/se: “¿Cómo hiciste para sobrevivir? Sólo un milagro lo explica: el milagro de la misericordia" (467).

La necesidad que tiene el adulto de volver al pasado para entender, junto con el oyente escogido, los hechos ocurridos, acusa la falta de nitidez, lo ininteligible que estos resultaron a los ojos del niño. El mundo que recuerda Fernando en "Voz en el teléfono" tiene la compleja cualidad de los lenguajes y enunciados equívocos, así como de las cosas sin sentido: vive en una casa enorme con habitaciones sin utilidad: dos escritorios cuando nadie escribe, cuartos de baño con dos lavatorios; le celebran su fiesta eliminando todos los elementos habituales de la casa para reemplazarlos por chucherías y cornetas que no suenan; las representaciones de títeres lo desconciertan porque la "Caperucita Roja me aterró como el lobo a la abuela" y la "Bella me pareció horrorosa como la Bestia" (288); los propios miembros de la familia se conducen de modo invertido: el cocinero que adora "lo amenazaba, en broma, con un enorme cuchillo lustroso"; y la madre, la más importante, en lugar de mentir, se las "arreglaba para pronunciar las palabras de un modo equívoco, como si se le enredara la lengua", dice Fernando, intentando defenderla. Afirmaciones cariñosas como: "mi madre era un amor"; "mi madre nunca mentía" (287); "Mi madre era un pan de Dios" (288); se contradicen con lo que, al menos, Fernando destaca en su relato: la vemos despedir injustamente al cocinero de la casa; y mantiene un amorío con el que las amigas llaman el barbudo o el duende (nombres "secretos" para este amante).

Por su parte, el oyente que ha escogido Fernando para contarle su secreto sigue con atención la conversación haciendo preguntas sobre un sinnúmero de detalles, y aunque en apariencia tiende a reparar en asuntos superfluos, como el final de un mueble chino 
tras el incendio de la casa, Fernando logra volver a lo que quiere confidenciar: su autoría del crimen. El habría sido el autor del incendio de la casa y, en particular, de la habitación donde estaban encerradas las madres. Él robó los fósforos, él juntó los papeles para armar el fuego, él decidió concentrarse en la habitación de las madres y no desperdiciar los fósforos en las niñeras, él las encerró con llave para que no pudieran salir.

Es esa decidida inclinación por revelarse como autor del incendio la que se relaciona con la necesidad de ser comprendido y, eventualmente, perdonado: “¿Ahora comprendes por qué no quise encender tu cigarrillo? ¿Por qué me impresionan tanto los fósforos? ¿No sabías que era tan sensible?" (291). Sin embargo, y a pesar de su claridad en identificar responsables, algo pareciera mantenerse oculto, en reserva, a pesar de sus intentos por contarlo todo. Algo que se vuelve absolutamente inasimilable y resistente al discurso, aparece ocultándose, desplazándose en metonimias, sinécdoques, sin ser dicho del todo.

Cuando los niños bajan a la plaza para desde allí ver cómo se incendia la casa, logran vislumbrar a las madres asomándose a la ventana, "pero estábamos tan interesados en el incendio que apenas las vimos. La última visión que tengo de mi madre es de su cara inclinada hacia abajo, apoyada sobre un balaustre del balcón" (291). Así como en aquel entonces Fernando evitó mirar a la madre ahogándose, hoy -junto con la complicidad del oyente- vuelve a desplazar su atención hacia el mueble chino y negarse a hablar de la madre y su relación con ella. Sin embargo, en ese continuo desplazamiento del secreto, algo logra ocultarse y decirse, finalizando así su confesión: "El mueble chino se salvó del incendio, felizmente. Algunas figuritas se estropearon: una de una señora que llevaba un niño en los brazos y que se asemejaba un poco a mi madre y a mí" (291). En la figura de porcelana estropeada -o el plumerito de primera comunión de la niña de "El pecado mortal", que pasa a adornar el ojal del sirviente- se concentra figurativamente un secreto que rehúye de su revelación.

Freud en La interpretación de los sueños, al ejemplificar su teoría con un sueño sobre su ejercicio profesional, confiesa haberle dado a su paciente, Irma, una solución sobre su malestar, que la habría llevado a abandonar la terapia. Este fracaso lleva al analista a replantear su método, descubriendo un nudo constitutivo a todo sueño/deseo: un secreto imposible de desentrañar. Asimismo parece cifrarse el secreto en estos cuentos. No pudiendo concentrar el secreto en la "cajita" para el caso-Dora -otro fracaso terapéutico: la "cajita" como solución lleva, esta vez, a Dora a abandonar la terapia-; ni en el mueble chino, ni en la porcelana, ni en el "plumerito", el sentido se desplaza y oculta, apartándose a la vista, a la solución definitiva.

\section{La palabra incomprensible de los dioses}

41 Ricardo Piglia, interesado en las formas narrativas del secreto -del género policial, la tragedia o la nouvelle-, articula un estrecho lazo entre la literatura y el psicoanálisis en su modo de construir un secreto: "El psicoanálisis construye un relato secreto, una trama invisible y hermética, hecha de pasiones y creencias, que modela la experiencia" (2014: 53), y que se erige en ese gusto, esa seducción por "admitir que en un lugar secreto experimentamos o hemos experimentado grandes dramas" (51). James Joyce, en este sentido, habría descubierto que las maneras de narrar del psicoanálisis y de construir la narración se organizarían a partir de un complejo sistema de relaciones 
que definen la trama, sin obedecer a una lógica lineal, "y que datos y escenas lejanas resuenan en la superficie del relato y se enlazan secretamente" (55).

No solo Joyce, sino que también los textos de Ocampo y Bombal se juegan en aquel entrecruce y anudamiento de la vigilia con los sueños, lo vivido y por vivir en ese borroso déjà $v u$, que sugiere una misteriosa conexión plena de un sentido secreto. En Amasijo de Marta Brunet, esta trama que enlaza distintos momentos de la historia del personaje central, Julián, aparece tematizada y representada con la imagen del "amasijo", esta mezcla de harina y agua que une tiempos, yoes y relaciones personales. Una metáfora para pensar la composición del sujeto y la práctica psicoanalítica. El personaje se analiza hasta que se convence "que nunca, nunca, iba a liberarme..., que mi vida entera estaba encerrada en ese círculo... No crea que sin lucha. Soy un psicoanalizado" (1962: 120). Luego intenta otro tipo de análsis en las conversaciones con una mujer desconocida y, paralelamente, explora la escritura de una obra de teatro que representa su tragedia personal. Así como Julián está convencido de que en algún lugar secreto ha experimentado grandes dramas, siguiendo a Piglia, hay también en esta novela aquello que el escritor argentino ve que comparten la tragedia y el psicoanálisis, y consistiría en esa "tensión entre el héroe y la palabra de los dioses, del oráculo, de los muertos, una palabra que venía de otro lado, que le estaba dirigida y que el sujeto no entendía. El héroe escucha un discurso personalizado pero enigmático, es claro para los demás, pero él no lo comprende, si bien en su vida obedece a ese discurso que no comprende" (2014: 59-60).

La historia de este dramaturgo se aborda desde dos perspectivas intercaladas: su pasado familiar, y un presente en que afronta sin entusiasmo el ensayo del estreno de su obra, al mismo tiempo que lucha angustiosamente por comprenderse. El relato del pasado, el proyecto artístico y la reflexión sobre la intimidad arman una sola trama confesional, que apunta a pensar, bajo la forma de un "amasijo", la composición del individuo. Una mezcla que se sabe hecha de materiales múltiples, "una arcilla oculta en lo íntimo de él, amasijo que va tomando forma y vida" (62), y que resulta imposible de desentreñar. "Cada uno con su cifra propia, sin lograr saberla. Buscándola desesperadamente (...) ¿Qué sabía él de sí mismo sino a través de súbitos resplandores...? (...) ¿Qué sabía él de sí mismo, de la verdad de sí mismo?" (1962: 62). El discurso enigmático del oráculo y los dioses se vuelve para el sujeto un misterio, un material secreto que busca descifrar a partir de su historia personal, de su trabajo literario y de la conversación confesional.

La historia de su pasado se concentra en la conflictiva relación con su madre. Narrada en tercera persona, esta versión la confirma Julián en su relato confidencial. La madre, siendo muy joven, habría perdido a su marido en un accidente automovilístico, del que ella sobrevive quedando para siempre postrada en la cama. Desde ahí cría a su hijo como si fuese una linda muñeca y a la que no le permite alejarse ni un metro de ella. Lo retiene consigo, al margen de la escolaridad y de toda relación con el mundo social hasta muy avanzado en edad. Con el tiempo y dificultad, Julián intentará escapar de la presión de la madre, viajando cada vez más lejos y por cada vez más tiempo. A pesar de ello, incluso ya muerta, sigue presente en cada mujer con la que intima; revive sus senos, su boca, su insistencia. Las mujeres, piensa con desesperación, "seguían siendo la fisura dolorosa por donde surgía el implacable pasado" (89); y cuando "voluntaria o involuntariamente recordaba su infancia se hallaba fijo en un caleidoscopio en que había una figura central: "ella". Y a su alrededor, infinitas móviles formas de colores, alucinantes, perturbadoras” (79). Como aquella trama secreta que describe Piglia, así se 
anuda el pasado y el presente en la imagen de un caleidoscopio. En la mitad se encuentra "ella", la figura innombrable que ocupa el centro de su mundo interior. Alrededor suyo, piezas que se reorganizan de distinta manera según el movimiento del juego. Piezas provenientes de distintos momentos temporales, piezas que enlazan pasado y presente, piezas capaces de hacer converger todo pensamiento y experiencia siempre a la inevitable figura de la madre.

A pesar de los eufemismos, "ella" y "eso" para referirse a su indecible problema con la madre y a su homosexualidad, respectivamente, el relato confesional de Julián busca rodear y acercarse a aquello innombrable:

No puedo decirlo... No puedo -gimió-. Caí en "eso" como en un pozo, lo mismo que hubiera podido tirarme de cabeza a un pozo, en la esperanza, creo... -vaciló y continuó-: No sé si me estoy justificando. Bueno, caí en el homosexualismo -rio con una suerte de estertor-. Ya está dicho. Con la esperanza de salvarme de lo otro. Y no me salvé de nada. A veces creo que lo que soy es sencillamente "eso". (122)

Lo indecible, lo innombrable, cuando se dice no significa nada ni resuelve nada. 0 , más bien, se mantiene resonando, igual de misterioso, igual de secreto como si no se hubiese dicho.

Será una extraña y cálida desconocida la que ayude a hilar la "urdimbre" del relato confesional. Serena, con rasgos de alguna etnia de Centro América y vestida a la usanza de las nativas de su país, llama la atención y se distingue por lo inadecuado de su abrigo en pleno verano y por la tranquilidad de sus pasos en pleno centro de la agitada ciudad. Sin pechos a causa del tratamiento contra un cáncer, la mujer le dará confianza a Julián precisamente por lo extraña, extranjera y poco familiar. A esta mujer desconocida le contará de "ella" y de "eso", y la mujer, como "las tejedoras de su país", irá "trabajando sobre la urdimbre que se le entregaba" (117). De esos hilos se irá desenredando su historia familiar y se irá reconociendo el vínculo autobiográfico con su escritura. Aparecerá la construcción de esos personajes que Julián vio "aflorar desde su subconsciente", que se le impusieron con frases sueltas, inquietándolo, sin poder librarse de su amenaza hasta que los hubo transformado en una obra. "Su propia vida es una confesión. Y en especial su obra" (110), sentencia la mujer.

Escritura confesional la de Amasijo y la de Julián. Una puesta en abismo que hace suponer la puesta en escena de algo parecido a "Amasijo" el día que se estrena la obra de Julián. Una confesión que requiere del cura, en su infancia, y de la hipnótica señora, después. “¿Por qué me confesaba?" -se pregunta- "Porque en los ojos del señor cura había idéntico mandato que en los suyos, señora. El mismo magnetismo. Igual al que me tiene aquí, crispado, violento, con ganas de huir, pero diciendo ante usted lo que creo mi verdad. Esa mísera parte de nuestra verdad que nos es dado conocer..." (118).

El secreto que busca confidenciarse en el presente de la conversación pospone su total develamiento, como si después de ello se anunciara el final de la vida del personaje y el de la literatura. La vida sostenida en la duración de la confesión y la narración, vuelven todo proyecto al lugar de la literatura, así como la literatura se torna en aquella posibilidad de mantener y comunicar lo inefable, indecible e íntimo de la vida. Antes de poner fin a su vida en el escenario donde se ha representado su obra, Julián retoma una reflexión sobre la división genérico-sexual. En la disposición de los ladrillos de la pared cree ver una composición "machihembrada", como se llama a la forma de engarzar las tablas en el piso. Y con ello, la pregunta acerca de si "habría un ignorado orden en la molécula, en el átomo, en que sus partes tenían género y de ahí su fusión” (179). El 
drama que escenifica Julián tiene que ver con la pregunta por "ella" y por "eso". Dice del enigma de la diferencia sexual, de la composición "machihembrada" del individuo, del género de las moléculas. $O$ dice del imposible desciframiento de la identidad sexual vivido como un drama.

La novela piensa el lugar de la confidencia como (des)conocimiento de sí mismo. Y el decir confidente como la escenificación de una conversación, que regresa a la literatura. La literatura estaría estrechamente ligada a la confesión y a la intimidad, rescatando el sentido inasible que la constituye. Así, cuando Julián identifica las tres realidades de la obra: "la suya escrita, esta otra representada por los actores y la que captaba el público" (92), destaca la imposibilidad de una "comprensión colectiva". "Existían -concluye- tantas obras como espectadores en el teatro" (92). A los silencios, los vacíos, ese decir ocultando (en eufemismos y puntos suspensivos) que hacen de la literatura misma un secreto, una revelación imposible; a ese secreto constitutivo se le suman los imposibles sentidos unívocos de la representación teatral, de la lectura y la recepción.

51 Así, la escritura literaria está vinculada a un sujeto confesional que es "parte de ese engranaje" secreto, "y el juego, cuando se está en él hay que jugarlo" (94), afirma Julián. Estamos hablando de una literatura comprometida, no en el sentido político, sino íntimo; que compromete al sujeto con su historia, su vida, sus secretos. Julián se cuelga de las poleas del escenario el día en que se estrena su obra. Escribe para alargar la vida y aplaza la vida para terminar su obra. Una vida suspendida en la duración de la escritura. Una escritura que pone en escena la vida, lo íntimo de la vida. Una escritura que no tiene más futuro que la vida misma. Una escritura que solo se explica con el final de la vida. Una escritura cuyo único compromiso es con el secreto y lo íntimo de la vida. Y con el secreto de la literatura.

La época en que escribieron estas tres autoras estuvo dominada por discusiones y decisiones estéticas y la adscripción a grupos literarios, movimientos artísticos y circuitos intelectuales. Un panorama liderado por figuras como Borges, Neruda, Victoria Ocampo, mientras estas tres autoras buscaban su voz, acomodándose a las tendencias de la época y tensionando su posibilidad de decir desde ahí. En este sentido, me parece que a diferencia de muchas escritoras del periodo, ellas logran sortear la crítica y la descalificación, ubicándose en los límites de las "reglas del arte" aceptadas por sus círculos, para asomarse a ese insondable secreto del que habla Luisa Valenzuela.

\section{BIBLIOGRAFÍA}

Bloom, Harold, La angustia de las influencias, Caracas, Monteávila, 1976.

Bombal, María Luisa, “Las islas nuevas”, Obras Completas (Compiladora: Lucía Guerra), Santiago, Editorial Zigzag, 2018, p. 147-167.

Bombal, María Luisa, “Testimonio autobiográfico”, Obras Completas (Compiladora: Lucía Guerra), Santiago, Editorial Zigzag, 2018, p. 273-290. 
Brunet, Marta, Amasijo, Santiago, Editorial Zigzag, 1962.

Dällenbach, Lucien, El relato especular (1977), Madrid, Visor, 1991.

Derrida, Jacques y Ferraris, Maurizio, El gusto del secreto (1997), Buenos Aires - Madrid, Amorrortu, 2007.

Fernández Porta, Eloy, En la confidencia, Barcelona, Anagrama, 2018.

Ocampo, Silvina, “El impostor", Autobiografía de Irene (1948), En Cuentos completos, Buenos Aires, Emecé, 2017.

Ocampo, Silvina, “Voz en el teléfono". La Furia (1959). En Cuentos completos. Buenos Aires:

Emecé, 2017.

Ocampo, Silvina, "El pecado mortal”, Las invitadas (1961), En Cuentos completos, Buenos Aires, Emecé, 2017.

Pardo, José Luis, “Un secreto a voces. Ensayo sobre la lengua de la intimidad”, Revista de la Universidad de México, p. 96-98

Piglia, Ricardo, “Los sujetos trágicos (Literatura y psicoanálisis)”, Formas breves, Editorial Debolsillo, 2014.

Piglia, Ricardo, “Secreto y narración” (2006), La forma inicial, Buenos Aires, Eterna Cadencia, 2016, p. $249-260$

Podlubne, Judith, Escritores del Sur. Los inicios literarios de José Bianco y Silvina Ocampo, Buenos Aires, Editorial Breatriz Viterbo, 2011.

Sommer, Doris, Ficciones fundacionales. Las novelas nacionales de América latina, México, Fondo de Cultura Económica, 2004.

Valenzuela, Luisa, Escritura y secreto, Madrid: Instituto Tecnológico de Estudios Superiores de Monterrey y Fondo de Cultura Económica de España, 2003.

\section{NOTAS}

1. Este artículo forma parte de los resultados del proyecto Fondecyt Regular 1210310, "Literaturas del secreto", dirigido por Andrea Kottow.

2. Un buen ejemplo es la novela Aves sin nido (1889) de Clorinda Matto de Turner, en que el sacerdote ad portas de la muerte confiesa una paternidad que hermana a los dos protagonistas enamorados, cuyo enlace prometía solucionar los problemas de abusos (cohecho, pederastia, racismo, entre otros) de la comunidad. Así, una vez conocida la noticia del incesto, se echa por la borda todos los planes políticos y de limpieza moral que los héroes de la historia venían trazando para terminar con las inmoralidades de las autoridades.

3. Al referirnos a ciertas narrativas de mediados de siglo XX estamos pensando -en el contexto de la investigación que lidera Andrea Kottow y se titula "Literaturas del secreto"-, en autores como Antonio Di Benedetto, Manuel Puig, Juan José Saer, Luis Gusmán, José Donoso, Mauricio Wacquez y Diamela Eltit, entre otros. Acojo acá la tesis central del proyecto sobre el lugar y el modo en que se organiza el secreto en algunas de las obras de estos autores y retomo uno de sus objetivos centrales, que busca establecer puentes entre la literatura argentina y chilena a partir del que creemos un interés común por el secreto, abriendo a su vez una entrada a las posibles diferencias 
en los modos de abordarlo y que podría develar ciertas particularidades de ambos campos culturales.

\section{RESÚMENES}

A partir de la revisión de algunos textos de Silvina Ocampo, María Luisa Bombal y Marta Brunet, escritos entre 1939 y 1962 y que tienen como tema central algún secreto -el familiar, el policial, del doble, el sexo-genérico, el de confesión, entre otros- se analiza la forma en que aquellos secretos son abordados, en cuanto a sus recursos técnicos y en términos narrativos y estéticos, y cómo estos procedimientos se ponen al límite o resultan insuficientes para decir lo indecible. Las tres autoras supieron navegar por las aguas de los dictámenes literarios, moviéndose en sus bordes para asomarse al vacío del secreto.

Nous examinons quelques textes de Silvia Ocampo, Maria Luisa Bombal et Marta Brunet, écrits entre 1939 et 1962, où il $\mathrm{y}$ a un secret comme thème central : de famille, de police, du double, du sexe générique, de la confession, entre autres. On analyse la manière dont ces secrets sont abordés, quant à leurs ressources techniques et en termes narratifs et esthétiques, et comment ces procédures s'avèrent insuffisantes pour dire l'indicible. Les trois auteures ont su naviguer dans les eaux des opinions littéraires, se déplaçant sur les bords pour se pencher dans le vide du secret.

This article examines texts authored by Silvina Ocampo, María Luisa Bombal, and Marta Brunet between 1939 and 1962 that share in common the central theme of secrecy: a family secret, a detective story, a doppelgänger, a revelation of sex/gender, and a confession, among others. The article analyzes the ways in which these secrets are approached through both technical devices and narrative and aesthetic choices, and how all of these are pushed to their limits or ultimately fall short in expressing the unspeakable. The three authors in question knew the waters of literary opinion, tracing their edges in order to peer into the void of secrecy.

\section{ÍNDICE}

Mots-clés: Secret, Bombal, Ocampo, Brunet

Palabras claves: Secreto, Bombal, Ocampo, Brunet

Keywords: Secret, Bombal, Ocampo, Brunet

\section{AUTOR}

\section{ANA TRAVERSO}

Universidad Austral de Chile

anatraverso@uach.cl 